\title{
Conditioned suppression of a positively reinforced shuttle response
}

\author{
JULIAN C. LESLIE and PAUL GARRUD \\ Department of Experimental Psychology, Oxford University, South Parks Road, Oxford OX1 3PS, England
}

\begin{abstract}
Rats were trained to run up and down an alleyway for sucrose reinforcement on a variable interval schedule. Differential aversive classical conditioning with auditory CSs was then conducted in a separate apparatus ("off the baseline") prior to those CSs being presented while the subjects were responding for sucrose in the alleyway. Once the effects of the CSs had extinguished, shock was reintroduced following one CS but not the other ("on the baseline" differential aversive classical conditioning). Both "off the baseline" and "on the baseline" conditioning resulted in conditioned suppression to the CS followed by shock, but little effect of the CS followed by no shock was found. In the "on the baseline" phase, total suppression of baseline responding occurred at moderate US intensities, and this appeared to result from the subject avoiding the location at which he was last shocked. At lower values, both baseline response rate and relative suppression ratio were functions of US intensity. The results are discussed in relation to the effects found in similar experiments using avoidance baselines.
\end{abstract}

Estes and Skinner (1941) found that food reinforced leverpressing was suppressed by a conditioned stimulus (CS) that was followed by an unconditioned stimulus (US) of an electric shock. Such conditioned suppression of operant behavior by a preaversive CS has also been found using avoidance baselines (Bryant, 1972). However, Rescorla and Solomon (1967) were able to find support for their motivational account of operant classical interactions from a number of studies carried out in the Pennsylvanian laboratories (e.g., Rescorla \& Lolordo, 1965; Rescorla, 1967). In general, these involved training dogs to jump over a hurdle on a Sidman avoidance schedule. On this schedule there is no exteroceptive cue for the response; shocks occur at fixed time intervals, the shock-shock interval, unless a response occurs, whereupon the next shock is postponed for a fixed time interval, the response-shock interval (Sidman, 1953). After a number of avoidance sessions, the avoidance sessions were alternated with differential aversive classical conditioning sessions in which hurdle jumping was prevented. During the subsequent avoidance sessions, presentation of the CS for shock (CS+) (but without the shock occurring) increased the rate of hurdle jumping and presentation of the CS for no shock (CS-) (which had been presented in the classical conditioning sessions but never followed by shock) decreased the rate of hurdle jumping. From such data it was plausibly argued that the CSs were producing changes in responding because they affected fear, which was maintaining the avoidance behavior.

More recent research has made this argument difficult to sustain. Hurwitz and his colleagues (Hurwitz \&

This research was undertaken while the first author was supported by a Research Studentship from the U.K. Medical Research Council and the second author was supported by a Research Studentship from the U. K. Science Research Council

The first author is now at the School of Biological and Environmental Studies, New University of Ulster, Coleraine, County Londonderry, Northern Ireland.

Reprints may be obtained from either author.
Black, Note 1; Hurwitz \& Roberts, 1969; Roberts \& Hurwitz, 1970) have shown that the avoidance respond. ing of rats in a Skinner box is disrupted and tends to be suppressed by presentations of a CS followed by shock, while Bryant (1972) found substantial suppression when the US was a severe shock. Scobie (1973) again found the same pattern of disruption (leading to more baseline shocks) and partial suppression. He points out that suppression is a very general result in leverpressing situations but acceleration has been found in shuttlebox and in wheel turning experiments (Weisman \& Litner, 1969). Although such acceleration is not an inevitable result (Scobie, 1972) it certainly occurs under some conditions. The pattern of these results with avoidance baseline raises doubts about the generality of the results obtained with positively reinforced baselines (e.g., Estes \& Skinner, 1941). Leverpressing situations have almost always been used. The suspicion that leverpressing behavior is readily disrupted and suppressed by presentations of CSs paired with appetitive or aversive USs is strengthened by Davis and Kreuter's (1972) experiment. They gave CS-food pairings to rats leverpressing on a Sidman avoidance schedule and found that the number of shocks increased during the CS, although total responding was little affected because of postshock bursts. This is an identical pattern to that found by Hurwitz and Black (Note 1) and Hurwitz and Roberts (1969). It would clearly be of value to transpose the Estes-Skinner procedure to a situation resembling the shuttlebox avoidance apparatus. The present experiment attempted to do this.

The operant used in this study involved running from one end of an alley to the other and pushing open the flap covering a tray in which sucrose solution was presented. Similar apparatus has been used by Frey, Eng, and Gavin (1972) and by Padilla (1971). However, in those studies the apparatus was not symmetrical; i.e., reinforcement could only be obtained at one end. 
Table 1

A Summary of the Procedure

All Subjects:

Continuous Reinforcement
Partial Reinforcement
VI $30 \mathrm{Sec}$
VI $1 \mathrm{Min}$
CS Habituation
CS Extinction
CS $.5 \mathrm{~mA}$ US

\begin{tabular}{lc}
\multicolumn{2}{c}{ Rat 1 } \\
\multicolumn{1}{c}{ CS } & Sessions \\
$.2 \mathrm{~mA}$ US & 28 \\
$.3 \mathrm{~mA}$ US & 16 \\
$.25 \mathrm{~mA}$ US & 8 \\
Ext. & 9
\end{tabular}

Followed by:

\begin{tabular}{cc}
\multicolumn{2}{c}{ Rat 5 } \\
CS & Sessions \\
$.2 \mathrm{~mA}$ & 28 \\
$.3 \mathrm{~mA}$ & 7 \\
$.4 \mathrm{~mA}$ & 8 \\
Ext. & 9
\end{tabular}

\begin{tabular}{cc}
\multicolumn{2}{c}{ Rat 9} \\
CS & Sessions \\
$.2 \mathrm{~mA}$ & 28 \\
$.3 \mathrm{~mA}$ & 15 \\
Ext. & 9
\end{tabular}

Rats 2, 6, and 10

$\begin{array}{llr}\text { CS } & .2 \mathrm{~mA} \text { US } & 43 \text { Sessions } \\ \text { CS } & \text { Ext. } & 9 \text { Sessions }\end{array}$

Additionally, the former study used gerbils, about which little is known in conditioned suppression situations, while the latter study did not involve conditioned suppression. In the present study rats were used in a symmetrical apparatus.

The major objective was simply to look at the effects of a CS paired with shock on this shuttling behavior. In addition, a differential conditioning procedure was used to see whether opposite effects of CS+ and CS- occurred, and the classical conditioning was carried out both "on the baseline" and "off the baseline." Whether "on the baseline" or "off the baseline" procedures are used normally depends on the experimenter's theoretical predispositions. Any operant-classical interaction can be seen as a variant of the Estes-Skinner procedure, where "on the baseline" conditioning is appropriate, or as a test situation for two-process learning theory, where "off the baseline" conditioning seems more sensible. Until directly comparable results are available from the two procedures, differences in results can be attributed to this variable (e.g., Hurwitz \& Roberts, 1969), although when the comparisons have been made the variable has been shown to be ineffective (Scobie, 1972; Van Dyne, 1971).

\section{METHOD}

\section{Subjects.}

Six male albino Wistar rats from the Oxfordshire Laboratory Animal Colonies, weighing approximately $250 \mathrm{~g}$ at the beginning of the experiment, were used. They were gradually introduced to a 23-h food deprivation schedule, and were maintained on this schedule for 2 weeks prior to and throughout the experiment, being fed for $1 \mathrm{~h}$ approximately $1 \mathrm{~h}$ after the last animal was run. They were numbered $1,2,5,6,9$, and 10 .

\footnotetext{
Apparatus

The apparatus consisted of an aluminum alleyway with two end boxes $20 \mathrm{~cm}$ square, and a central runway section which
}

was $60 \mathrm{~cm}$ long and $17 \mathrm{~cm}$ wide. The walls were $31 \mathrm{~cm}$ high and the floor was made out of $506-\mathrm{mm}$ diam aluminum rods, equally spaced throughout the apparatus and wired with every tenth rod in parallel. Electric shock was produced by a Grason-Stadler constant current scrambled shock generator, No. 1064 GS. In each end wall of the alley there was a Perspex flap covering a foodtray. A motor driven dipper gave the subject access to $0.1 \mathrm{ml}$ of $10 \%$ sucrose solution (by weight) when reinforcement was programmed. The roof was made out of smoked Perspex, which overhung the sides of the alley by $4 \mathrm{~cm}$ and left a gap of $2 \mathrm{~cm}$ above the walls for ventilation. This made an effective one-way vision screen when the internal lights were on. Five 8-ohm loudspeakers were let into the roof, positioned equidistantly along the whole length with their centers $20 \mathrm{~cm}$ apart. These were wired in series. Four 2.8-W houselights were also let into the roof; these were spaced $25 \mathrm{~cm}$ apart. Auditory stimuli were provided by an Advance Instruments LF oscillator, No. J2E, and a Campden Instruments click generator, No. CI-258. The oscillator was set at $870 \mathrm{~Hz}$ and the click generator at 20 clicks $/ \mathrm{sec}$. Two photobeams were placed $4 \mathrm{~cm}$ outside each of the two end boxes.

A grid box was also used. This had aluminum sides $29 \mathrm{~cm}$ high and a grid floor 22 by $24 \mathrm{~cm}$. The grid could be connected to the shocker. When in use, it was placed directly under one of the loudspeakers in the roof of the alley. The experiment was controlled and the data collected by a Data General Corporation NOVA 800 computer programmed in ACT (Millenson, 1971).

\section{Procedure}

The subjects were habituated to the alley and allowed to feed at both ends of it for two sessions. No difficulty was experienced in getting them to run from one end to the other. They were then placed on daily 30 -min sessions for the whole experiment. Throughout, the reinforcement consisted of 3-sec access to the sucrose solution. This was timed from the moment the subjcct operated the microswitch attached to the tray flap. There was a total of four recorded responses (the operation of the two tray flaps and two photobeams), and the computer compiled the following data: the total number of operant responses (the operation of one tray flap followed by the operation of the other, i.e., a one-way trip down the alley); the time spent in each section of the alley (divided into two end sections and a center section by the photobeams); the total number of responses in PreCS, CS, and PostCS periods, each of $30 \mathrm{sec}$, for both CSs (see below).

The conditions and total number of sessions run by each subject in each condition are shown in Table 1 . They were stabilized on continuous reinforcement, run for four sessions on partial reinforcement with three out of four responses reinforced, and then stabilized on a VI 1-min schedule. Following this, the "off the baseline" conditioning began. Two sessions of CS habituation, in which 30-sec presentations of both tone and clicker occurred on a VI 5-min schedule, were followed by a single CS-US pairing session carried out in the gridbox. This consisted of 20 presentations of the tone for $30 \mathrm{sec}$ followed by a $0.5-\mathrm{sec} 0.5-\mathrm{mA}$ shock, and 20 presentations of the click stimulus for $30 \mathrm{sec}$ followed by no shock. The order of presentation was randomized, and the intertrial interval was variable with a mean of 2 min.

Subjects were then returned to the shuttle alley for CS-extinction; in this phase the procedure was the same as for CS habituation. In subsequent "on the baseline" conditioning, the CSs were the same as in the "off the baseline" conditioning for Subjects 1, 5, and 9 and were reversed for Subjects 2, 6, and 10 . The procedure remained the same as CS-extinction, except that $0.5-\mathrm{sec} 0.5-\mathrm{mA}$ shocks occurred after each appropriate CS. As can be seen in Table 1, each subject was run at a variety of US intensities but none of the other conditions was altered. The US 
intensity was manipulated in order to produce partial stable suppression for each subject. Five subjects (Nos. 2, 5, 6, 9, and 10) had an inhibition test session between the last CS-US pairing session and CS-extinction. In this, both CSs were presented simultaneously a number of times, but only half the presentations were followed by shock. The last phase, CS-extinction, was identical to the CS-extinction that had occurred between the "off the baseline" and the "on the baseline" phases.

\section{RESULTS}

The major results of the experiment are shown in Figure 1. This gives the baseline response rates, response rates during the $\mathrm{CS}+$ and response rates during the $\mathrm{CS}-$ for each rat during all phases of the experiment. These data are presented for three-session blocks.

Before CS presentations began, the VI rates were between 6 and 10 responses/min, which meant that the subjects were making 6 to 10 responses/reinforcement on average. The effect of CS presentation alone was slight, but the trend was towards suppression of responding.

In CS-xtinction, after conditioning "off the baseline," all subjects showed greater suppression to the CS+ on the first block of sessions than to the CS-. The

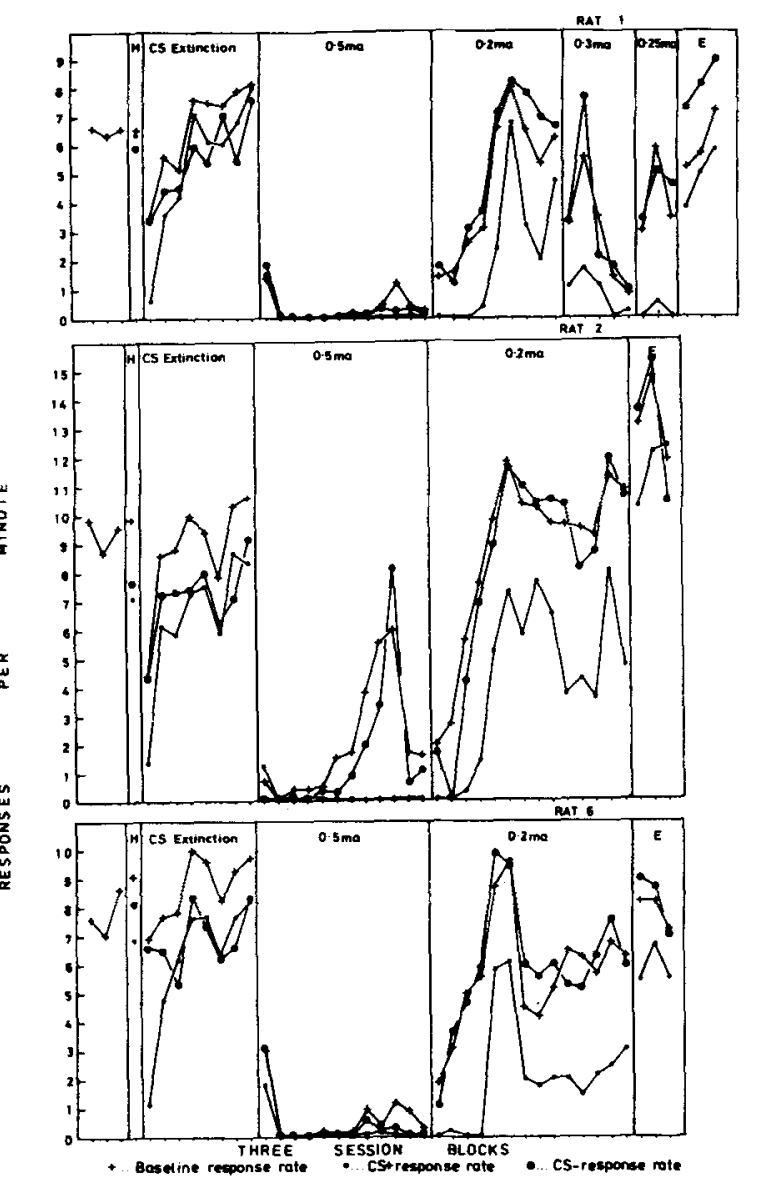

Figure 1a. Response rates on the baseline and during CS+ and CS - for Subjects 1, 2, and 6 for all phases of the experiment. baseline rate was also suppressed, but not so much as the rate in CS+. These effects disappeared at different rates for different subjects; by the eighth block (i.e., the 22nd-24th sessions) all the baseline rates had recovered to their original levels, but slight suppression to the CS+ still occurred. Over early blocks, the rate in CS- fell between the CSt and the baseline rates. In the last 4 blocks, however, the rate was the same as in CSt.

Suppression ratios, calculated as CS rate/CS rate + PreCS rate (Kamin, 1961), for the initial 10 presentations of CS+ and CS- are shown in Figure 2. Matched $t$ tests on the difference scores between PreCS and CS rates for these first 10 trials in each animal showed significant suppression to the CS+ in all 6 animals $(t=5.40,5.94,5.69,9.63,5.84,3.55 ;$ df $=9 ; p<.001$ for Rats 1, 2, 5, 6, 9 and $p<.01$ for Rat 10) and there was no significant suppression to the CS- in 4 subjects $(t=0.54,0.16,1.25,1.14$ for rats $2,5,9$, and 10 respectively; $d f=9, p>.20$ in each case). For the other two subjects, the CS- produced some suppression $(\mathrm{t}=2.09,2.74 ; \mathrm{df}=9, \mathrm{p}<.10$ and .05 for Rats 1 and 6 respectively) but matched tests on the difference between $\mathrm{CS}+$ and $\mathrm{CS}-$ ratios showed a

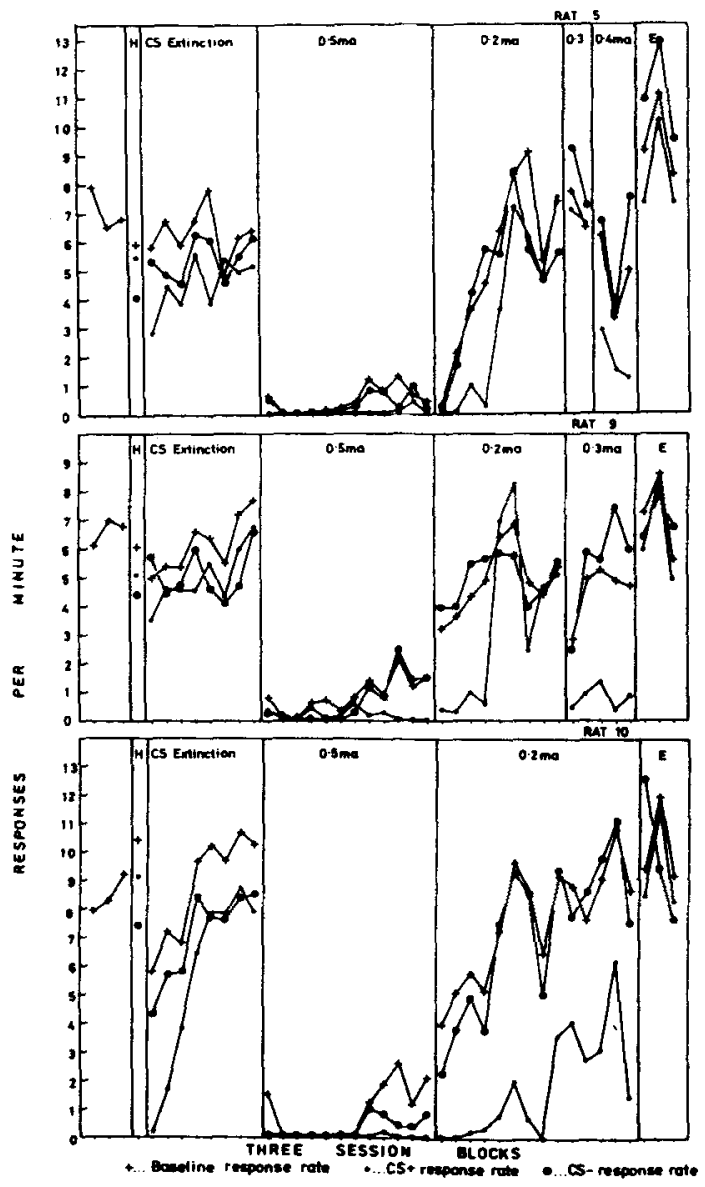

Figure $1 \mathrm{~b}$. Response rates on the baseline and during $\mathrm{CS}+$ and CS - for subjects 5, 9, and 10 for all phases of the experiment. 

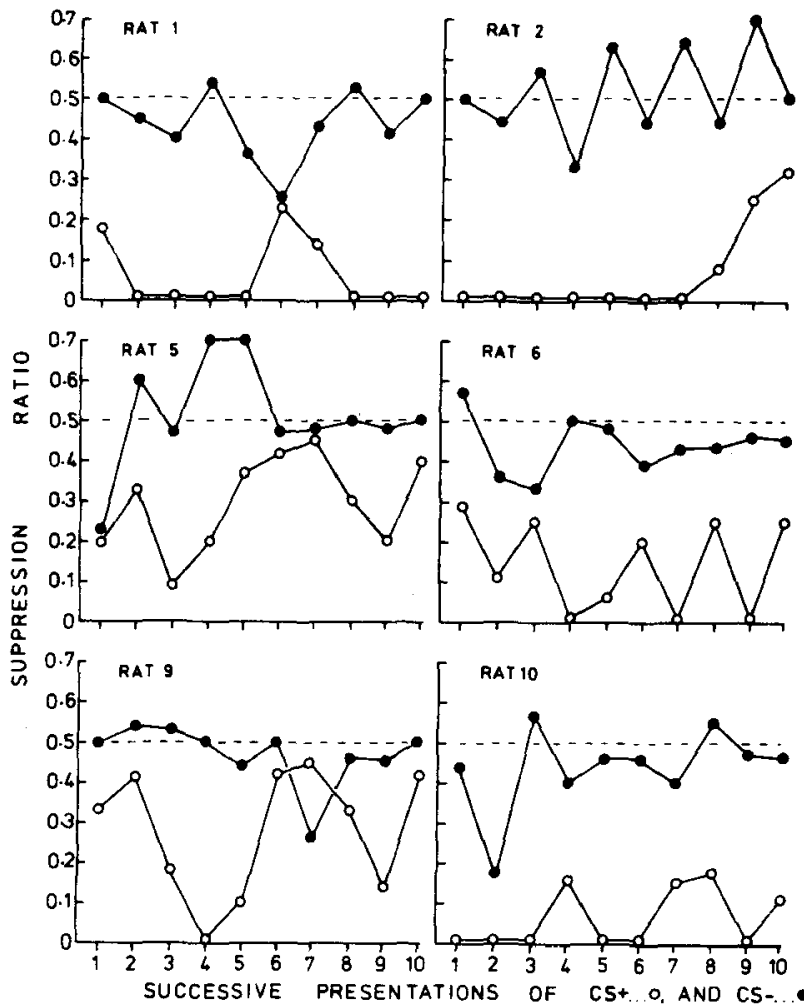

Figure 2. Suppression ratios for the first ten CS+ and CSpresentations for each subject.

significant difference in both cases $(t=6.37,4.67$; $\mathrm{df}=9 ; \mathrm{p}<.001$ and .01 for Rats 1 and 6 , respectively).

Introduction of $0.5-\mathrm{sec} 0.5-\mathrm{mA}$ shock USs following $\mathrm{CS}+$ presentations completely suppressed responding in all subjects. Baseline responding recovered slightly over the last six blocks, but suppression to the CS+ was total for all subjects in the last block of this phase. Subject 2

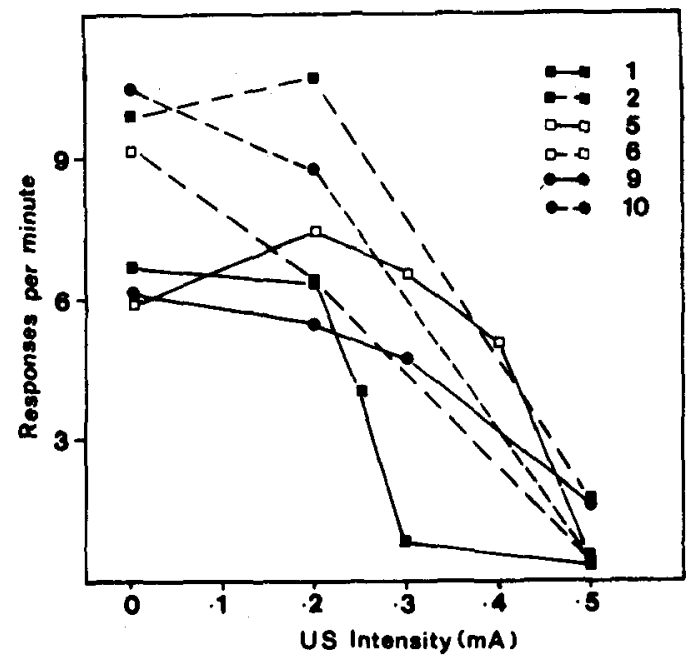

Figure 3. Baseline response rate as a function of US intensity. The data shown are for the last block of sessions in each condition. Baseline rate is calculated as the average for all non-CS time.

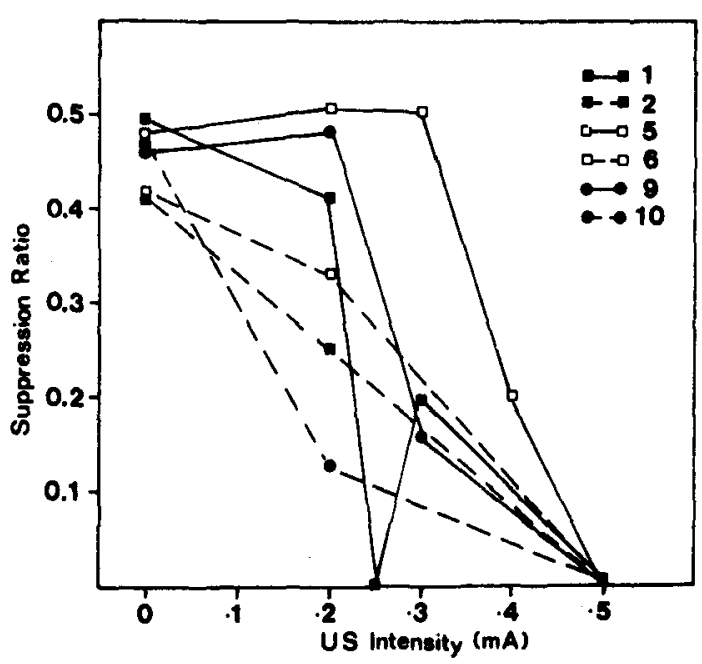

Figure 4. Suppression ratios as a function of US intensity. The data shown are for the last block of sessions in each condition.

showed a great deal more recovery than the others, but it was not sustained (see Figure 1). In this phase CSrate seemed closely related to baseline rate when the latter was above a minimum level.

US intensity was subsequently manipulated for each subject until a level was found where stable partial conditioned suppression occurred. This was at $0.25 \mathrm{~mA}$ for Rat $1,0.4 \mathrm{~mA}$ for Rat $5,0.3 \mathrm{~mA}$ for Rat 9 , and $0.2 \mathrm{~mA}$ for Rats 2,6 , and 10 . It can be seen from Figure 1 that baseline rate was a function of shock intensity. This is shown explicitly in Figure 3, which gives the baseline rates for the last block of sessions in each "on the baseline" condition and in the original CS habituation.

Figure 4 gives the suppression ratios (again calculated as CS rate/CS rate + PreCS rate) also for the last block of sessions in the same conditions. It can be seen that with increasing US intensity, responding is increasingly suppressed by the CS+ despite the concomitant decrease in baseline rates. Throughout the "on the baseline" conditioning phases, CS - rate closely paralleled baseline rate for all subjects. In Figure 1 it can also be seen that in the "on the baseline" conditions with US intensity less than $0.5 \mathrm{~mA}$, all subjects showed a fairly constant decrease in response rate during CS+ at any particular US intensity, despite large variations in rate between successive blocks of sessions.

The pattern of responding within CS+ periods was examined for those conditions that produced partial conditioned suppression. Four rats showed a consistently lower but nonzero rate in the final $10 \mathrm{sec}$ than in the remainder of the CS+ period. No consistent effect was found with the other two rats.

The single inhibition test session did not reveal any systematic effects of the CS-. Three subjects showed rates intermediate between their prior CS+ and CSrates when $\mathrm{CS}+$ and $\mathrm{CS}-$ were presented together, but 
the other two showed rates similar to their previous CS+ rates. In Table 2 the results of the inhibition test are shown. Suppression ratios for those presentations that were followed by shock are shown separately from those followed by no shock, but it should be remembered that these two types of trial could not be discriminated by the subjects.

In the final CS-extinction phase, baseline rates rose rapidly and equalled or exceeded the rates in original VI training and CS habituation. CSt rates rose equally rapidly and the resulting suppression was minimal. $\mathrm{CS}$ - rates continued to track the baseline rates.

\section{DISCUSSION}

No difficulty was found in establishing the operant response on a VI schedule. The eventual rates of $6-10$ responses/min are of course low by direct comparison with leverpressing rates on the same schedule; this is because each response required the subject to run a meter. Low frequencies of reinforcement have not often been used in discrete trial runway situations [although Weinstock (1958) provides an example] but this study establishes that similar behavior can readily be maintained in a free operant situation where the number of responses/reinforcement rose to 15 in some sessions. A similar result, though in a rather different apparatus, was found by Padilla (1971).

All subjects showed slight suppressive effects to the auditory CSs when presented alone. This differs markedly from the findings of Rescorla and Lolordo (1965) for dogs and Scobie (1972) for rats, on avoidance schedules. In both cases CS presentation alone produced a significant and persistent increase in shuttling (or hurdling). It may be that in aversive situations auditory stimuli tend to facilitate activity, as rats also find it difficult to use an auditory stimulus as a cue to inhibit a running response in a "go - no go" discrimination using shock as the reinforcer (Frontali \& Bignami, 1973). Although the response in the present experiment necessitated contact with each end of the apparatus, intermittent observation showed that all subjects learned to do this very economically without pausing, and their behavior was topographically very similar to that seen when rats are shuttling in an avoidance situation. It therefore seems that the conditioned acceleration and the acceleration to CS alone found in the earlier studies is a result of an interaction between the reinforcer used and the topography, as consistent suppression was found throughout the present experiment.

The suppression to the CSt seen in this study has throughout been referred to as "conditioned suppression" because it apparently resulted from the pairing of the CS+ with shock. We should, however, be wary of concluding that the suppression is the result of "true" classical conditioning. Because of the single-subject design of this study, only some of the controls necessary
Table 2

Suppression Ratios on Inhibition Test and on the Previous Day

\begin{tabular}{rcccc}
\hline Rat & \multicolumn{2}{c}{ Test Day } & \multicolumn{2}{c}{ Previous } \\
& $\begin{array}{c}\text { CS+ \& CS } \\
\text { Shock }\end{array}$ & $\begin{array}{c}\text { CS+ \& CS }- \\
\text { No Shock }\end{array}$ & CS+ & CS- \\
\hline 2 & .49 & .29 & .29 & .52 \\
5 & .40 & .38 & .29 & .66 \\
6 & .29 & .25 & .30 & .58 \\
9 & .68 & .37 & .27 & .40 \\
10 & .18 & .04 & .11 & .46 \\
\hline
\end{tabular}

to prove that point were run. While we may take comfort from the fact that no substantial suppression occurred to the CS in the CS-habituation phase nor to the CS-during discrimination training, we also need to know whether US presentations alone would produce subsequent suppression to the $\mathrm{CS}$ in this apparatus, and whether subjects given a truly random control procedure (Rescorla, 1967) would show suppression to the CS.

The most striking finding of the present experiment was seen in the first "on the baseline" phase. The introduction of 0.5 -sec $0.5-\mathrm{mA}$ shocks totally suppressed all responding and recovery was slight and sporadic. This shock level is one which would be expected to produce only partial conditioned suppression in a leverpressing situation [cf. Millenson \& de Villiers (1972) who used very similar parameters and shock density]. Indeed, although baseline suppression does occur in leverpressing situations (Millenson \& Dent, 1971), it is relatively transient. All the evidence points to there being a cause of baseline suppression in the present study other than the generalization from CS+ to apparatus cues that occurs in leverpressing situations. The nature of this cause is suggested by the following observations. Very occasionally (not more than once for each subject) an experimenter intervened during a session in which the rat was not running at all. It was found that if the rat was removed from one end of the alley and placed at the other end, he immediately ran back to his original position. Additionally, it was noted that the rats did not appear afraid; they did not crouch, freeze, or defecate. The rat did not remain at the same end of the apparatus for the whole of a session because each US elicited running to the other end. On arrival the rat sometimes completed the operant response by pushing open the tray flap, and then remained relatively inactive until the next US presentation.

This pattern of behavior resembles one-trial passive avoidance: after a shock in a particular situation (in this case one of the end sections of the apparatus) the subject refuses to return to it, or shows a greatly increased latency of response. The odd feature of this experiment was that the avoided location changed from trial to trial. This occurred because the subject remained at the "unshocked" end until the next shock, and then ran to the other end. The rats were using situational cues as conditioned stimuli (CSs) for shock as well as the auditory stimulus that pervaded the whole apparatus. 
Presumably this does not occur normally in Skinner boxes because the rat associates the shock simply with being in the box, rather than being in any particular part of it. This would appear to be an instance of subjects avoiding a CS associated with shock similar to that found by Leslie (1974), who, using the same apparatus, showed that rats will withdraw from a localized preaversive CS in the absence of any operant contingencies. An alternative explanation is that the association of the apparatus with the $0.5-\mathrm{sec} 0.5-\mathrm{mA}$ shock elicits freezing. This can be rejected for two reasons: firstly, as already mentioned, there was no evidence of such behavior; secondly, there is no reason why the same mechanism should not suppress all behavior in the Skinner box, but there is plenty of evidence that it does not. Millenson and de Villiers (1972) found only partial conditioned suppression of responding using the same shock parameters and the same type of shock generator.

The other phases of the experiment produced more predictable results. The "off the baseline" conditioning was effective, but the suppression established to the CS+ diminished steadily with succeeding sessions. There appeared to be generalization of suppression from CS+ to $\mathrm{CS}$ - in this phase. The baseline was not greatly suppressed even in the first block of sessions, although the shock that had been used was the same as in the subsequent "on the baseline"phase where total suppression occurred. This strengthens the case for the operation of a particular mechanism in the latter phase.

When US intensity was varied both baseline rate and relative suppression ratio were affected. In these phases CS - rate was closely related to baseline rate, but an inhibition test did not give any indication of stimulus control by the CS-.

In conclusion, the major results of this experiment are:

(1) Conditioned suppression of a positively reinforced shuttling (running) response can be established, but although differential conditioning succeeded in establishing a good discrimination between the CS+ and the CS-, no clear effect of the CS- was found.

(2) These results held for "off the baseline" and "on the baseline" conditioning procedures.

(3) At a moderately high US intensity the baseline responding was also suppressed in the "on the baseline" procedure. This appeared to result from the subject avoiding the location at which shock last occurred. (4) At lower US values, both baseline response rate and relative suppression ratio were functions of US intensity.

\section{REFERENCE NOTES}

1. Hurwitz, H. M. B., \& Black, R. E. Risk taking behavior under conditions of punishment. Paper presented to Southeastern Psychological Association, 1968.

\section{REFERENCES}

Bryant, R, C. Conditioned suppression of free-operant avoidance. Journal of the Experimental Analysis of Behavior, $1972,17,257-260$.

Davis, H., \& Kreuter, C. Conditioned suppression of an avoidance response by a stimulus paired with food. Journal of the Experimental Analysis of Behavior, 1972, 17, 277-285.

Estes, W. K., \& Skinner, B. F. Some quantitative properties of anxiety. Journal of Experimental Psychology, 1941, 29, 390-400.

Frey, P., Eng, S., \& Gavin, W. Conditioned suppression in the gerbil. Behavior Research Methods \& Instrumentation, 1972 , 4, 245-249.

Frontali, M., \& Bignami, G. Go - no go avoidance discrimination in rats with simple "go" and compound "no go" signals: stimulus modality and stimulus intensity. Animal Learning \& Behavior, 1973, 1, 21-24.

Hurwitz, H. M. B., \& Roberts, A. E. Suppressing an avoidance response by a preaversive stimulus. Psychonomic Science, $1969,17,305-306$.

Kamin, L. J. Trace conditioning of the conditioned emotional response. Journal of Comparative and Physiological Psychology, $1961,54,149-153$.

Leslie, J. C. The mechanism of conditioned suppression. Unpublished D. Phil. thesis, Oxford University, 1974.

Millenson, J. R. A programming language for on-line control of psychological experiments. Behavioral Science, 1971, 16, 248-256.

Millenson, J. R., \& Dent, J. G. Habituation of conditioned suppression. Quarterly Journal of Experimental Psychology, $1971,23,126-134$.

Millenson, J. R., \& de Villiers, P. A. Motivational properties of conditioned anxiety. In $R$. M. Gilbert and J. R. Millenson (Eds.), Reinforcement: Behavioral analyses. New York: Academic Press, 1972.

Padilla, A. M. Analysis of incentive and behavioral contrast in the rat.Journal of Comparative and Physiological Psychology, $1971,75,464-470$.

Rescorla, R. A. Pavlovian conditioning and its proper control procedures. Psychological Review, 1967, 74, 71-80.

Rescorla, R. A., \& Lolordo, V. M. Inhibition of avoidance behavior. Journal of Comparative and Physiological Psych. ology, 1965, 59, 406-412.

Rescorla, R. A., \& Solomon, R. L. Two process learning theory : relationships between Pavlovian conditioning and instrumental learning. Psychological Review, 1967, 74, 151-182.

Roberts, A. E., \& Hurwitz, H. M. B. The effects of a pre-shock signal on a free-operant avoidance response. Journal of the Experimental Analysis of Behavior, 1970, 14, 331-340.

Scobie, $S$. R. Interaction of an aversive Pavlovian conditioned stimulus with aversively and appetitively motivated operants in rats. Journal of Comparative and Physiological Psychology, $1972,79,171-188$.

Scobie, $S$. $R$. The response-shock interval and conditioned suppression of avoidance in rats. Animal Learning \& Behavior, 1973, 1, 17-20.

Sidman, M. Avoidance conditioning with brief shock and no exteroceptive "warning signal." Science, 1953, 118, 157-158.

Van Dyne, G. Conditioned suppression with a positive US in the rat. Journal of Comparative and Physiological Psychology, $1971,77,131-135$.

Weinstock, $\dot{S}$. Acquisition and extinction of a partially reinforced running response at a 24-hour intertrial interval. Journal of Experimental Psychology, 1958, 56, 151-158.

Weisman, R. G., \& Litner, J. S. The course of Pavlovian excitation and inhibition of fear in rats. Journal of Comaparative and Physiological Psychology, 1969, 69, 667-672.

(Received for publication April 9, 1975. Revision accepted September 16,1975.) 